\title{
The characteristics of the entrepreneur: the contrasts of the Cuban and Mexican case
}

\section{Las características del empresario: los contrastes del caso cubano y mexicano}

\author{
CRUZ-CORDERO, Teresa*†, HERNÁNDEZ-DE LIRA, Antonieta and RAMÍREZ-RODRÍGUEZ, \\ Judith Esperanza
}

Universidad Tecnológica de Aguascalientes. Blvd. Juan Pablo II, La Cantera. 20200 Ex Hacienda, Puebla. Mex.

ID $1^{\text {st }}$ Author: Teresa Cruz-Cordero

ID $1^{\text {st }}$ Coauthor: Antonieta, Hernández-de Lira

ID $2^{\text {nd }}$ Coauthor: Judith Esperanza, Ramírez-Rodríguez

DOI: $10.35429 / J G E .2019 .4 .3 .16 .25$

Received February 25, 2019; Accepted June 27, 2019

\begin{abstract}
The current environment requires the company to be aware of it with commitment. Correspondence must be taken into account of the way in which work is done with emphasis on skills to enhance the management team and its management actor, which is of interest in virtually all countries of the world, its economic impact and the occupation individuals are significant, the cultural aspect permeates in the practice of it, and therefore in the results it generates. The objective of the study is to spread the distinctive characteristics of the entrepreneur in two different contexts, Cuban and Mexican, influenced by the elements of cultural dynamics. The inputs of various authors were analyzed and the results are mainly based on the analysis on the basis of agreed criteria for the collection of information through the application of a survey that includes some key elements in the management. Finally, it is concluded that in both nations there are common features in the individual aspects, however, the prevailing culture is considerably unequal, and the effects on the leadership function differ.
\end{abstract}

Company, Entrepreneur, Culture Dynamics

\begin{abstract}
Resumen
El entorno actual exige a la empresa una toma de conciencia con compromiso. En correspondencia hay que tener en cuenta la forma de laborar con énfasis en habilidades de potenciar el equipo de dirección y su actor de dirección el empresario, lo que es objeto de interés en prácticamente todos los países del mundo, su impacto económico y en la ocupación de los individuos son significativos, el aspecto cultural permea en la práctica del mismo, y por ende en los resultados que genera. El objetivo del estudio es difundir las características distintivas del empresario en dos contextos diferentes, el cubano y el mexicano, influenciados por los elementos de la dinámica cultural. Se analizaron las aportaciones de diversos autores y los resultados están basados principalmente en el análisis sobre una base de criterios consensuados de la recopilación de información mediante la aplicación de una encuesta que recoge algunos elementos claves en el accionar de la gestión directiva. Finalmente se concluye que en ambas naciones existen rasgos comunes en los aspectos individuales, sin embargo, la cultura que impera es considerablemente desigual, y los efectos en la función de dirección difieren.
\end{abstract}

Empresa, Empresario, Dinámica de la cultura

Citation: CRUZ-CORDERO, Teresa, HERNÁNDEZ-DE LIRA, Antonieta and RAMÍREZ-RODRÍGUEZ, Judith Esperanza. The characteristics of the entrepreneur: the contrasts of the Cuban and Mexican case. RINOE Journal-General Economics. 2019. 3-4: 16-25.

\footnotetext{
* Correspondence to Author (email: teresa.cruz@utags.edu.mx)

$\dagger$ Researcher contributing first author.
} 


\section{Introduction}

The current company is bound by innovation, new strategies and business models, as well as the launch of new products, to act based on technological and human processes that allow it to improve organizational efficiency and customer focus. Throughout history, the company has undergone significant changes in the organizational structure, according to the different instrumented growth models. In this context, you can see different contrasts between Mexico and Cuba.

Some hydro-warm and Havana companies in different contexts have been fortunate to prevail and grow in the face of demands, global competition, economic crises and the strong technological pressure of today, where managers are considered as paradigms and leaders for companies and have known to direct and redirect collaborative efforts based on their strategies. The work presented is one of the results presented in a Research Project on the "Influence of Cultural Dynamics in Entrepreneurship" by Cruz, T. (2016). and the question arose, since one of the authors is born in Cuba, what are the distinctive characteristics of the entrepreneur in two different contexts, the Cuban and the Mexican?

In this sense, the objective of this work is to disseminate the distinctive characteristics of the entrepreneur in two different contexts, the Cuban and the Mexican, influenced by the elements of cultural dynamics.

The previous question led to the design of a survey, which includes some key elements that entrepreneurs attribute to the actions of its management and a non-probabilistic sample was chosen for convenience for its application.

All available information was properly processed, criteria and points of view were exchanged between the authors, in order to elaborate the work on the basis of agreed criteria, as well as the conclusions where some ideas are provided that can be implemented in order to achieve a better and more efficient business fabric that favors a substantial improvement of the situation in the company. Finally, it is concluded that in both nations there are common features in the individual aspects, however, the culture that prevails is considerably unequal, and the effects on the management function differ.

\section{Methodological aspects}

The methodology used to carry out the work was based primarily on the critical review of the selected literature as the one of greatest interest for the topic of business, business and cultural dynamics, as well as the derivation of the authors' own ideas in this regard. To this was added the design of a survey, which includes key elements that entrepreneurs attribute to the actions of its management and its application to Cuban, and Mexican, businessmen, who contributed their main experiences, on what they consider characterizes them.

A non-probabilistic sample was chosen for convenience for its application and it was constituted by 220 businessmen in the City of Aguascalientes and 210 businessmen in Havana City in the industrial and service sectors.

The collection of information in the case of Aguascalientes was carried out by 28 students of the Masters in Business Administration and Education Sciences of the Universidad del Valle de México, Aguascalientes Campus, as part of a final evaluation project.

In the case of Havana City, a person was used who, due to his employment relationship with different businessmen, was able to apply it.

Both in Aguascalientes and in Havana City, the Survey was carried out by means of a pollster who had the opportunity to listen to some criteria and only the disposition of the businessman was needed.

The Survey is divided into 5 sections. In the first one, the general information of the entrepreneur is requested, such as age, time worked in the company, last degree of studies and position held in the company.

In the second section certain characteristics are presented that an entrepreneur must have by carrying out a weighting, among other aspects. The third section is dedicated to the desired values and their importance.

In the fourth section certain characteristics are presented for a company to be successful. In the last section some characteristics are raised that a leader and those of an entrepreneur. 
In the case, the City of Aguascalientes, processing and prior analysis was carried out by students who were distributed in different teams and who presented the results of their work as part of their final evolution.

The authors subsequently processed and analyzed all the information to reach more comprehensive and generalizing conclusions. In the case of Havana City, all the information collected was processed and delivered, which was subject to analysis to arrive at the results. Subsequently, the comparison and analysis of the information on the basis of agreed criteria of the authors was carried out, to make the conclusions presented in this work.

\section{Results}

At present there is talk of new business paradigms that reflect how the organization thinks and operates and that are part of its culture, which is the support of the strategy towards a sustainable company.

This requires: a manager prepared with knowledge to develop and achieve the objectives of your business, a proactive direction, to participate in the actions of the organization, and therefore a business culture that facilitates interaction with the environment.

The organizational culture influences the characteristics of an entrepreneur, although there are general characteristics that can identify them, such as security, risk adoption, independence, vision, creativity, among others.

To understand the organizational culture, we must consider the different elements that make up the cultural dynamics, so it is necessary to emphasize this, in order to adequately analyze the most effective ways of knowing the characteristics that identify the culture in an organization and its influence on the manager For a better understanding of the dynamic nature of the organizational culture, it is necessary to refer to four fundamental factors that are closely related, which also explain why cultures arise and survive, National and international environment, Leadership, Culture functions , Cultural Learning Socialization of Culture.

- National and International Environment.
The economic, political, social and environmental situation of the world has been transformed enormously in recent years, which determines the need to implement new ideas and approaches, derived from a new thought about business management, which has to adapt more and more to the changes that have taken place not only nationally, but also internationally and that are intertwined with each other.

An increasingly globalized world, with immense scientific technical transformations and gigantic transnational corporations, which dominate the planet, has conditioned, among many other consequences, important transformations in the international norms of competition, increasingly ferrous and difficult to complete.

If the environment is analyzed within the scope of the organization, it projects towards it a multifaceted set of trends: economic, political, ideological, cultural, religious, social, among others, marked by the evolution and historical development of society, where the character of the patriarchal hegemonic systems of male domination in the different societies, is evidenced at present in certain values and norms that privilege men with respect to their power and organizational leadership.

The environment can be classified into microenvironment and macroenvironment. Examples of the first may be customers, suppliers, competition, higher bodies, government agencies, others.

Unlike the microenvironment, the organization cannot directly influence the macroenvironment, so its only alternative is to adapt its microprocesses to macro-trends, such as the economic crisis, inflation, demographic and environmental trends.

The analysis leads us to the reflection that the organizational culture in its interaction with the environment is consolidated, when trying to adapt to the substantial modifications that are operated on it, which has an important influence on the process of formation, consolidation and cultural change. 
The environment has an influence on business innovation since as Drucker (2000) proposes in its seven sources of innovation, three of them are related to the social environment that surrounds us, they are: demographic changes, changes in the perception of reality and new knowledge and technology. As can be seen, there are aspects that link the environment and innovation to cultural dynamics and which cannot be ignored.

\section{- Leadership.}

Leadership influences the functions of culture (internal integration, external adaptation) and has a fundamental role in training, consolidation and cultural change and its role cannot be underestimated.

A leader must clearly communicate to his collaborators and followers his values, vision, mission, objectives, strategy, proposal and work program to align the efforts in the same direction. This should not in any case constitute a formality, but should be a daily work in the interaction with its employees, at whatever level they are. They must be, at the same time, agents of innovation and change that guide, develop and grow their organizations or groups.

Being innovative and creative, devising new solutions, challenging the way things are done and proposing to do different things, is important and necessary in a very competitive world, which is advancing rapidly in the context of unprecedented technological change, which you need to understand in its right dimension and analyze and synthesize effectively the information they receive.

Flexible leaders are required, who can adapt quickly to unknown or different situations, for those who have not been trained and for those who do not have experience and information, a leadership oriented to cultural change and prepared for it.

A leader can be considered, when a group chooses, accepts, recognizes and establishes with him a commitment to achieve a common mission and objectives and therefore, it is essential that he share the values he prioritizes with his collaborators.
It can be pointed out that leadership influences business culture, since it decides on resources, information, reward and punishment, autonomy, control, innovation, as well as incorporating behaviors, habits, language and norms, among others.

It is essential to understand that the leader plays a significant role in the roots of culture levels (visible or not), but without the group itself, there is no such and, therefore, each member of the group has one more participation or less prominent in terms of its own unity and the degree of consolidation of its culture. The importance of the group in training and cultural dynamics is obvious.

\section{- Functions of Culture.}

In the process of culture formation, Identity is created as a function, given by the set of fundamental characteristics of the organization, where the levels of culture mentioned above intervene. Identity distinguishes each organization and manifests itself within two other processes, which are vital, which Schein (1994) has called: Internal Integration and External Adaptation.

External Adaptation is a fundamental function, since it projects the organization environment relationship. This allows subsistence by adapting to a turbulent, aggressive environment, such as the current one and also in the case of its participation in a different environment, such as an investment or business development in another country.

Internal Integration is one of the functions of the organizational culture, since it is born, develops and transforms from the need of the group itself to exist and remain as such.

This function is the unification of the group, in the sense of its adaptation, training and consolidation on the basis of the elements shared by the members that form them, while External Adaptation, is nothing more than survival in terms of responses to environment in which the group is located and that maintains a constant interaction relationship, which may even jeopardize its own existence, being this a strong element in the formation and consolidation of the innovative organizational culture. 
The internal should not be separated from the external, because of its great interrelation, but rather to focus them as a systemic unit and, therefore, in constant interaction and mutual influence. Around the company a group of other cultures that emit different positive and negative forces moves, understand these as threats and opportunities of the environment that move in a spiral and help or not to it, which at the same time moves projecting its own strengths and weaknesses.

As can be seen, the Internal Integration function can only be seen within the group, because although it as such has no material existence isolated from the environment where it arises and, to some extent, determines its creation, given that the organization has its own life ; it needs integration and it achieves it to the same extent that it consolidates itself as such and develops its own styles, common language and conceptual categories, group boundaries and inclusion and exclusion criteria, hierarchical order, power and authority mechanisms, communication, interrelations, systems of stimulation and sanctions, shared sense of belonging.

The functions of internal integration and external adaptation are interlinked and interdependent, the first conditions the second in the sense that allows the group's own existence and, in turn, the effort for survival and adaptation to and from the environment makes that integration be achieved and that it clearly identifies whether we are facing a flexible and innovative culture or not.

\section{- Cultural learning or Socialization of Culture.}

The adaptation process that new workers go through is known as Cultural Learning or Cultural Socialization. This process is extremely complex, since some of the basic elements of culture such as: norms, values and beliefs or basic assumptions of the group (organization) are transmitted to the new members, so that they share them in order to join the same, otherwise, in many cases, you must leave it.

In this process, the culture is selfperpetuating through the learning by the new members of the basic elements of the same, but, in turn, it is renewed and in its constant dynamics, assimilates new values related or not (although convergent) to their believes.
The person who arrives at an organization goes through a period of adaptation and learning during which he receives much more than he gives, during the first phase of this process, but depending on the degree of integration of the culture of that organization and how divergent may be their own values with respect to it, the new member will be incorporated faster or not to assimilate the cultural patterns of the group. If this is not the case, there will be a confrontation or inconsistency of values between the individual and the organization, with the corresponding problems that this entails. This new member will join the organization faster or not, assimilating the cultural patterns of the group and may, in turn, in a second phase farther or closer, incorporate new elements into it.

In summary, cultural learning has four phases: entry, assimilation, transformation and perpetuation. It follows from this the sense of commitment, its motivation, and its results in terms of productivity and even its permanence in time in the organization.

There are different mechanisms to carry out this process. Many of them are linked to the direction of the human factor, such as training, training, forms of reward, the role of the leader in the organization, innovation and the strength of the synergy emanating from the groups. In this sense, it can be said that innovation can also be assumed in the organizational culture through the socialization process.

The socialization process has an objective character, so it is very important that its existence is known and that it participates in its facilitation to contribute to the solution of the problems of external adaptation and internal integration that take place in the organization and are part essential of the functions of your culture.

\section{Businessman}

Because of the amount and depth of the tasks that arise in the management processes, it could be thought that the entrepreneur and his closest collaborators have to be geniuses or people with an over-dimensional talent, to carry out the strategies and make good decisions. 
It is common to hear in this sense, from positions of high stalls, critical judgments and demands of the entrepreneur as something that has to be strictly a model, little framed in the normal or extraterrestrial configuration that above all things has no right to be wrong, or err.

These perceptions of some people, generally not committed to the objectives of the organization, is not a necessary or even valid condition, they can also have harmful consequences for the manager and the company, since veiled criticism or covert reality only make deviations last, accentuate an unfair ideal and undermine the cohesion of the members and the image of it.

The entrepreneur is a group social entity, a facilitator driver, a coordinating planner organizer, a social science practitioner of organizational behavior and the maximum responsible, decision maker.

He is a common person, with goodness and virtues and with the attribute of accepting and being able to make mistakes, the latter characteristic that can be minimized by directing his intelligence to the integration of teamwork throughout the organization, and to the training of the contribution of all its members. It is distinguished by the responsibility of achieving results with its effort and through everyone's, in conditions of efficiency and effectiveness, of high working spirit and in current times in renovating directions. With objectivity you should think about your training and that of others, lead the learning process of the entire organization. This requires a high sense of direction and wisdom to choose the sources that provide it.

Its action and strength fundamentally decide the strength of technological and organizational innovation in its entity. Researchers, based on their own specialties, have given different degrees of integration to the elements they take for the characterization of entrepreneurs. Thus, greater emphasis can be found on the dependence of personality, direction on tasks or people, power, authority, leadership, situations or values, among the most relevant.

\section{The Habanero Businessman}

The results show some key elements related to the Business Mentality, which the Cuban businessmen themselves in Havana attribute to their managerial work, which are: rapid response to $40 \%$ challenges, decision making even in situations of ambiguity and crisis $23 \%$, adaptability and flexibility $21 \%$, perseverance and determination $16 \%$. As one of the characteristics with greater success is appreciated among the businessmen of Havana corresponds to the rapid response to challenges with $40 \%$, following the decision making even in situations of ambiguity and crisis with $23 \%$ being in third place with $21 \%$. Adaptability and flexibility, in fourth place, with $16 \%$ perseverance and $16 \%$ determination. Given the economic situation in this country, they are essential in the entrepreneur, to channel the changes that are manifested in their work context. Rapid response to challenges, decision making with ambiguity and crisis, adaptability and flexibility, as well as perseverance are fundamental in their work strategies.

\section{Situations that manifest at work}

The main feature that has been presented is the operability, represented in $96 \%$ of the entire sample, followed by bureaucracy with $91.5 \%$, conformism with $90.2 \%$ with a. Then a characteristic is presented that is not so appreciated, but nevertheless the conformism with $57.5 \%$ is presented in several companies. In addition, it was stated: Little teamwork, Uncertainty, individualism, this appreciates in the fulfillment of activities and tasks, as well as that there is no tendency to teamwork something that should be the reason for actions to encourage it because of its importance in the achievement of the objectives.

Features that a management team must have.

The businessmen surveyed in Havana City conclude that high expectations must be met for this management position. The main characteristics are the following: clarity of the organizational mission, common vision and objectives, shared norms and values, effective communication. 
In relation to the sense of belonging, it was not taken into account what denotes difficulties that can be manifested mainly, in the absence of commitment disinterest and demotivation.

Group cohesion is one of the most important variables of any group, as it expresses the feeling of unity of the members in terms of attitudes, values, language, goals to be obtained and actions to be undertaken. This indicator fluctuates according to the existing business climate. In this case we do not have enough elements to make a generalization.

Regarding job satisfaction, they stated that they do not feel high job satisfaction, nor can they fulfill their aspirations within the company and that they consider that they receive material and moral stimuli but that they are not yet sufficient.

\section{Qualities of the Havana manager}

There are many qualities that describe a person who is in front of a company or business. The respondents indicated that in their consideration those that manifest themselves in Havana businessmen are the following: respect for those around them, initiative, collectivism, fulfillment of commitments, quality of work, discipline.

Desired values. that are manifested with more force, are the following: honesty, responsibility, entrepreneurship, quality, social recognition, solidarity.

This result coincides with some of the main contributions of the consulting process (related to cultural elements), according to data collected in the partial and final reports of these processes and other actions carried out by one of the authors, as well as (Otero, D. , Villanueva, M. and S. García 1999) and in the investigation of (Gutiérrez and Morales 1999). The manifested values must be located first of all in the incipient creation of an organizational culture associated with values such as: aggressiveness, flexibility, entrepreneurship, creativity, adaptability, solidarity, family welfare, self-improvement. However, there are values that do not favor organizations, including bureaucracy, egalitarianism, noncompliance with plans and setting goals at all costs.

\section{Entrepreneurial Profile.}

Respondents believe that a person with an entrepreneurial profile in Havana City should have the following characteristics: perseverance, take risk, discipline, responsibility, respect, innovation.

\section{The Aguascalentense Businessman.}

Some key elements related to the Business Mentality are shown, which the Mexican businessmen themselves in Aguascalientes attribute to their managerial work, which are: Adaptability and flexibility. $26 \%$, Perseverance and determination. 22\%, Reliability. 19\%, Quick response to challenges. 17\%, Learning capacity. $16 \%$.

As one of the characteristics with greater success is appreciated among the businessmen, it corresponds to that of adaptability and flexibility with $26 \%$, following perseverance and determination with $22 \%$ and thirdly being reliability with $19 \%$. Adaptability and Flexibility are essential in the entrepreneur, to channel the changes that are manifested in the context they work. Perseverance and determination in the work they develop in the company is vital today, where customers are not loyal and seek the best options in their favor. In the case of reliability, it is essential in their work strategies, projects and employees.

\section{Situations that manifest at work.}

The main feature that has been presented is the operability, represented in $80 \%$ of the entire sample, followed by egalitarianism with $72.5 \%$. Then two other characteristics are presented that are not so appreciated, but nevertheless they are presented in several companies: bureaucracy $37.5 \%$ and conformism $30 \%$.

It also manifested: lack of commitment, lack of discipline, mediocrity. It is a situation to consider for future improvement actions that consider these three characteristics.

Features that a management team must have. Entrepreneurs interviewed from Aguascalientes conclude that whoever occupies these types of positions must have high expectations. 
The main characteristics are the following: clarity in the organizational mission, shared norms and values, sense of belonging, group cohesion, mutual trust. Effective Communication is an essential process for management, and it was not taken into account what denotes difficulties that can be manifested mainly, not so much for lack of information, because sometimes it is left over, but for the use of it. Group Cohesion is one of the most important variables of any group, as it expresses the feeling of unity of the members in terms of attitudes, values, language, goals to be obtained and actions to be undertaken. This indicator fluctuates according to the existing business climate. In this case, there are not enough elements to make a generalization, which requires further study.

Regarding job satisfaction, respondents find a notable satisfaction in their work environment, however, they still consider that companies do not fulfill their aspirations compared to the moral and material stimulus received. manager.

Qualities of the Aguascalentense

There are many qualities that describe a person who is in front of a company or business. The respondents indicated that in their consideration those manifested in the hydro-warm entrepreneurs are the following: love of work, fulfillment of commitments, quality of work, discipline, respect for those around him, initiative, collectivism.

The fulfillment of commitment, the quality of work, discipline, are at the same level of importance in $22 \%$, the highest percentage is manifested in respect and the least significant, collectivism which highlights the presence of individualism in compliance of activities and tasks, as well as that there is no tendency to work in a team, something that should be the reason for actions to encourage it because of its importance in achieving the objectives.

Desired values. The values that are most desired by entrepreneurs are the following: Adaptability $82.5 \%$, Quality $77.5 \%$, Honesty, 75\%, Responsibility 75\%, Respect $72.5 \%$
It can be seen that adaptability is an important value in entrepreneurs in the industrial and service sectors in the City of Aguascalientes, or that it allows the ability to accommodate changes without compromising the achievement of business objectives.

If a comparison is made with the Adaptability and Flexibility characteristics of your Business Mentality, this value can be validated more strongly.

It is important to point out that significant values may vary depending on the culture of the company, in the case of the hydrochlorides that were surveyed, the main values are: Honesty, Responsibility and Respect.

Values are manifested that do not favor organizations, including bureaucracy and goal setting at all costs.

\section{Entrepreneurial Profile.}

Respondents believe that a person with an entrepreneurial profile in the State of Aguascalientes, which should have as characteristics: creativity, commitments to results, respect, responsibility, innovation, discipline.

\section{Conclusions}

Different authors dedicated to studies in the field of management conclude in their research that there is no scheme or pattern of absolute characteristics to classify an entrepreneur, this has a lot to do with the activity carried out by the company and with the management team and the environment. For this reason we can affirm that there is no single profile or particular psychological model The entrepreneur and the associated actions are conditioned in a special way by the organizational culture of the country and the company in question, an issue to which the attention it requires is not necessarily given.

- Entrepreneurs in the two countries with small differences maintain a traditional and paternalistic leadership, continue without giving importance to the performance of their human resources. 
- Communication in both countries is not effective, there is no such communication between managers and employees, this leads to staff not knowing what needs to be done.

- A frame of reference can be seen in the results for the analysis of the business mentality in the City of Aguascalientes and the City of Havana and its projection in both.

- Entrepreneurs are focused on results and even achieve them, but do not feel satisfied at work, so the lack of motivation in both Mexico and Cuba, this is still a problem of importance.

- The businessmen of both countries have preference to perform the tasks individually, so this makes the mission materialization and the realization of the vision difficult.

- Leadership in both countries emphasizes the outcome and not the essence of their staff, so there is no humanistic approach to their actions, and this is a key point to achieve business success.

- Significant values may vary depending on the culture of the company and the country, so there was no marked similarity.

- The Cuban businessman, in entrepreneurial activity, is full of uncertainties, ranging from government decisions, to the national and international environment, which becomes increasingly complex. In this sense, the Mexican businessman has greater opportunities and fewer regulations that limit his entrepreneurial actions.

- In the Entrepreneurial Profile there are no marked similarities. There is a different entrepreneurial culture influenced by multiple aspects, such as the excess of existing regulations and controls in Cuba, which imply ethical problems associated with entrepreneurship to the emphasis on curricula at the different levels of education of private and public institutions that empower it, as in the case of Mexico, which is not manifested in the education system in Cuba.
Final reflection.

- Integrally consider all the factors involved in cultural dynamics, given their particular importance in sustainability and business competitiveness.

- We must work on cultural change to get closer to a profile of the entrepreneur that allows a real business improvement.

- It is necessary not to lose sight of the human essence, the challenge is to know how to communicate it and without a doubt in its actions.

\section{References}

Contin, P. (2007) Características distintivas de los emprendedores y los empresarios establecidos: evidencia a partir de los datos REM de Navarra, i. recuperado en https://www.researchgate.net/profile/Ignacio_Pi lart/publication/271847799_Caracteristicas_dist intivas_de_los_emprendedores_y_los_empresar ios_establecidos_evidencia_a_partir_de_los_da tos_REM_de_Navarra/links/54d4b6d50cf2970e 4e6383ae.pdf

Cruz, T. (2000): El Sistema Empresarial, Cultura y Consultoría. Folletos Gerenciales. No.3. CCED. MES.

Cruz, T. (2000): Fundamentos Metodológicos para el Estudio de la Cultura Organizacional. Tesis Doctoral.

Cruz, T. (2004): La Empresa Estatal en Cuba. Una Aproximación a la Caracterización de su Empresario. Colectivo de Autores. 15 Años del Centro de Estudios de la Economía Cubana. Editorial Félix Varela. La Habana

Cruz, T. [2005] Una Reseña de la Evolución de la Empresa Cubana. Cuba / Centro de Estudios de la Economía Cubana. Universidad de la Habana.

Cruz, T. (2015): Estudio de Valores Organizacionales con Enfoque de Género: Ponencia IX Coloquio de Investigación Nacional e Internacional de Cuerpos Académicos. UAA. México. 
Cruz, T. (2016): Particularidades propias del Emprendimiento en la Economía Cubana. Publicado en memoria electrónica, ISSN: 23959711, noviembre

Cruz, T. (2017): El Emprendimiento los Contrastes del Caso Mexicano y cubano. Publicado en Revista Iberoamericana Indexada. ISSN 2334-2501 http://www.reibci.org/, febrero

Otero, D., Villanueva, M. y S. García: (1999) "La consultoría como un Proceso de Cambio en la Cultura Organizacional". Centro de Estudios de la Economía Cubana, La Habana.

Gutiérrez, O. y R. Morales (1999): Organizaciones y Gerencia en Cuba. Apuntes para un Diagnóstico." Centro de Estudios de la Economía Cubana, La Habana. 